\title{
ATRIBUTOS FÍSICOS DO SOLO EM SISTEMA DE INTEGRAÇÃO LAVOURA-PECUÁRIA SOB PLANTIO DIRETO( ${ }^{(1)}$
}

\author{
Mastrângello Enívar Lanzanova ${ }^{(2)}$, Rodrigo da Silveira \\ Nicoloso ${ }^{(3)}$, Thomé Lovato ${ }^{(4)}$, Flávio Luiz Foletto Eltz ${ }^{(5)}$, \\ Telmo Jorge Carneiro Amado ${ }^{(4)}$ \& Dalvan José Reinert ${ }^{(5)}$
}

\begin{abstract}
RESUMO
A compactação do solo é um dos principais fatores responsáveis pela queda da produtividade das culturas agrícolas. Por isso, o impacto causado pelo pisoteio bovino sobre o solo e os conseqüentes reflexos nos atributos físicos densidade do solo, porosidade do solo, resistência mecânica à penetração e infiltração de água no solo, em área manejada sob sistema integração lavoura-pecuária, foram investigados em experimento de campo, no município de Jari, na região do Planalto Médio do Rio Grande do Sul, Brasil. Foram avaliados três sistemas de manejo da pastagem de inverno (aveia-preta, Avena strigosa Schreber + azevém, Lolium multiflorum Lam.), caracterizados pela freqüência de pastejo: (1) Sem Pastejo (SP), (2) Pastejo a cada 28 dias (P28) e (3) Pastejo a cada 14 dias (P14). Além disso, foi avaliada a influência da cultura de verão, soja [Glycine max (L.) Merr.] ou milho (Zea mays L.), em rotação com as pastagens de inverno, em amenizar ou agravar a ação compactadora do pisoteio bovino. A compactação do solo, avaliada pela sua densidade, concentrou-se na camada de $0-0,05 \mathrm{~m}$ de profundidade, porém houve redução de sua macroporosidade até a camada de 0,10-0,15 m, no sistema com a maior freqüência de pastejo (P14). A resistência mecânica do solo à penetração atingiu valores de 2,61 e 2,49 MPa nos tratamentos P14 e P28, respectivamente, nas
\end{abstract}

\footnotetext{
(1) Parte da Tese de Mestrado do primeiro autor apresentada à Universidade Federal de Santa Maria - UFSM. Recebido para publicação em março de 2006 e aprovado em junho de 2007.

(2) Professor Assistente da Universidade Estadual do Rio Grande do Sul - UERGS. Doutorando em Engenharia Agrícola na Universidade Federal de Santa Maria, UFSM. Rua Cipriano Barata 47, CEP 98600-000 Três Passos (RS). E-mail: mastrangellolanzanova@uergs.edu.br

${ }^{(3)}$ Doutorando em Engenharia Agrícola na Universidade Federal de Santa Maria - UFSM. Av. Roraima s/n, CEP 97105-900 Santa Maria (RS). Bolsista CAPES. E-mail: rsnicoloso@mail.ufsm.br

(4) Professor Adjunto do Departamento de Solos, UFSM. E-mail: tlovato@smail.ufsm.br; tamado@smail.ufsm.br

(5) Professor Titular do Departamento de Solos, UFSM. E-mail: feltz@ccr.ufsm.br; dalvan@ccr.ufsm.br
} 
profundidades de 0,05 e $0,08 \mathrm{~m}$, enquanto as áreas que não foram pastejadas mantiveram valores inferiores a 1,66 MPa. A taxa de infiltração de água no solo foi alterada significativamente pelo pisoteio bovino e pela cultura de verão antecedente. Com a cultura de milho, o solo mostrou-se menos sensível ao pisoteio bovino, ao passo que com a cultura de soja na maior freqüência de pastejo (P14) a taxa de infiltração de água no solo foi reduzida. A cultura de soja proporcionou os maiores valores de macroporosidade nas camadas avaliadas e, quando conjugada à menor freqüência de pastejo (P28) ou à ausência de pastejo (SP), observaram-se as maiores taxas de infiltração de água no solo.

Termos de indexação: pastejo rotativo, compactação do solo, pisoteio animal, manejo do solo, infiltração de água, pastagem cultivada.

\title{
SUMMARY: SOIL PHYSICAL ATTRIBUTES IN INTEGRATED CATTLE RAISING-CROP PRODUCTION SYSTEM UNDER NO-TILLAGE
}

\begin{abstract}
Soil compaction is one of the most important reasons for decrease in crop yield. The impact of animal trampling on integrated beef cattle raising-crop production systems were studied to evaluate the changes in soil physical properties (bulk density, porosity, soil resistance to penetration and soil water infiltration). The field experiment was carried out in Jari, in the mid-plateau region of Rio Grande do Sul State, Brazil. Three management systems of winter pastures (black oat; Avena strigosa Schreber + ryegrass; Lolium multiflorum Lam.) were studied under different grazing frequencies: (1) No grazing (NG), (2) grazing every 28 days (G28) and (3) grazing every fourteen days (G14). The summer crops soybean (Glycine max (L.) Merr.) or corn (Zea mays L.), as antecedent crop in rotation to the winter pastures, were also studied to measure the increasing or decreasing effects on compaction by animal trampling. The greatest effects of animal trampling were concentrated in the top soil layer $(0$ to $0.05 \mathrm{~m})$, but under the highest grazing frequency (G14) macroporosity was reduced down to the 0.10-0.15 m layer. The soil resistance to penetration had peaks of 2.61 and $2.49 \mathrm{MPa}$ in the G28 and G14 treatments, respectively, in the 0.05-0.08 layer. In the ungrazed areas the values remained lower, around 1.66 MPa. Soil water infiltration was significantly affected by animal trampling and by the previous summer crop. In the case of corn area, the soil was less sensitive to cattle trampling, unlike in the areas following soybean, where the highest grazing frequency (G14) reduced the water infiltration rates. Soybean induced higher values of macroporosity in the evaluated soil layers; when related with lower beef cattle density or ungrazed pastures, the rates of water infiltration and accumulated infiltration were higher.
\end{abstract}

Index terms: integrated cattle raising-crop production systems, no tillage, rotational grazing, soil compaction, animal trampling, infiltration, soil management.

\section{INTRODUÇÃO}

O avanço da atividade agrícola com a exploração de culturas anuais de grãos, como a soja e o milho, provocou redução de $12 \%$ das áreas de pastagens naturais no Rio Grande do Sul (RS) entre 1985 e 1996 (IBGE, 1996), as quais constituem a base forrageira da atividade pecuária neste Estado (Moojen \& Maraschin, 2002). Em 1996, cerca de $16 \%$ da superfície agrícola do RS encontrava-se sob sistemas mistos de exploração agrícola e pecuária (IBGE, 1996). Contudo, até o momento ainda existe carência de informações para indicar adequados sistemas de manejo das pastagens de inverno para essas áreas, os quais diferem consideravelmente daqueles de áreas manejadas exclusivamente para produção de grãos ou exploração pecuária (Nicoloso, 2005).

Segundo Albuquerque et al. (2001), a compactação do solo causada pelo intenso tráfego de máquinas e implementos agrícolas e pelo pisoteio animal tem sido apontada como uma das principais causas da degradação de áreas cultivadas em sistema de integração lavoura-pecuária. O processo de compactação reduz a densidade e a macroporosidade do solo, aumenta a resistência deste para o crescimento radicular, em condições de baixa umidade, e reduz a sua oxigenação, 
quando úmido (Marschner, 1995). Em solo compactado, o sistema radicular concentra-se próximo à superfície (Muller et al., 2001), tornando a planta mais susceptível a déficits hídricos e com limitada capacidade de absorver nutrientes em camadas subsuperficiais (Rosolem et al., 1994).

O grau de compactação provocado pelo pisoteio bovino é influenciado pela textura do solo (Correa \& Reichardt, 1995), sistema de pastejo (Leão et al., 2004), altura de manejo da pastagem (Cassol, 2003), quantidade de resíduo vegetal sobre o solo (Braida et al., 2004) e umidade do solo (Betteridge et al., 1999). No entanto, o efeito do pisoteio animal sobre as propriedades físicas do solo é limitado às suas camadas mais superficiais (Trein et al., 1991; Bassani, 1996), podendo ser temporário e reversível (Moraes \& Lustosa, 1997; Cassol, 2003).

Normalmente, as determinações de densidade e de porosidade do solo são as avaliações mais comuns e difundidas para identificar camadas compactadas no solo, porém a resistência mecânica deste à penetração, expressa pelo índice de cone, também está diretamente relacionada com o estado de compactação do solo e pode ser uma medida mais sensível para identificar a compactação, especialmente em camadas pouco espessas (Abreu et al., 2004). A infiltração de água no solo é considerada uma avaliação adequada para estimar sua qualidade física e estrutural (Leonardo, 2003), sendo fortemente influenciada pelo grau de compactação do solo, diminuição da porosidade e tamanho e continuidade de poros (Moraes, 1984).

Trein et al. (1991) observaram que, após aplicação de elevada taxa de lotação animal em curto período de tempo, houve aumento da resistência do solo à penetração mecânica, diminuição da macroporosidade e redução significativa da infiltração de água no solo na camada de 0-0,075 m de um Argissolo Vermelho cultivado com pastagens de inverno. Bertol et al. (1998) observaram resultados semelhantes ao avaliarem diferentes taxas de oferta de forragem de uma pastagem natural da Região Fisiográfica Depressão Central do Rio Grande do Sul, quando aplicaram taxas menores de 4 e $8 \%$ em relação a taxas de 10 a $16 \%$ de oferta de forragem.

Flores (2004) não encontrou diferença significativa na densidade e na porosidade de um Latossolo submetido ao pastejo de inverno em pastagem constituída por aveia-preta (Avena strigosa Schreber) e azevém (Lolium multiflorum Lam.), manejada a alturas variando de 0,10 a $0,40 \mathrm{~m}$. Cassol (2003) encontrou aumento na infiltração de água diretamente proporcional ao incremento da altura de resíduo da pastagem, evidenciando a degradação da qualidade do solo quando se utiliza elevada pressão de pastejo, em áreas de integração lavoura-pecuária sob sistema plantio direto.

O presente trabalho teve por objetivo avaliar alterações em algumas propriedades físicas do solo induzidas pela utilização de diferentes freqüências de pastejo em pastagens de inverno e a influência do aporte de palha e crescimento do sistema radicular das culturas da soja e do milho na redução da compactação do solo provocada pelo pisoteio bovino.

\section{MATERIAL E MÉTODOS}

Para desenvolver esta pesquisa, foi instalado um experimento de campo em área pertencente à Agropecuária Capitão Rodrigo, situada no município de Jari, RS (longitude de $54^{\circ} 13$ ' W, latitude de $29^{\circ} 17^{\prime}$ 'S e altitude de $441 \mathrm{~m}$ ), na região do Planalto Médio do Estado do Rio Grande do Sul, Brasil. O clima da região é do tipo Cfa 1 , segundo classificação de Köppen, com precipitação pluvial e temperatura média anual variando de 1.558 a $1.762 \mathrm{~mm}$ e 17,1 a $17,9^{\circ} \mathrm{C}$, respectivamente (Brasil, 1973). O solo do local é descrito como um Argissolo Vermelho-Amarelo alumínico típico (Embrapa, 1999).

Até o ano de 2001, antes da instalação do experimento, a área era mantida sob pastagem natural com a exploração de bovinocultura de corte, em sistema de pastejo extensivo. Em outubro de 2001, por ocasião da implantação do experimento, a camada de solo de 0-0,10 m foi amostrada, e os resultados da análise granulométrica e da fertilidade do solo foram os seguintes: $280 \mathrm{~g} \mathrm{~kg}^{-1}$ de argila, $281 \mathrm{~g} \mathrm{~kg}^{-1}$ de areia total, $433 \mathrm{~g} \mathrm{~kg}^{-1}$ de silte, $\mathrm{pH}-\mathrm{H}_{2} \mathrm{O}=4,90, \mathrm{P}=$ $2,70 \mathrm{mg} \mathrm{dm}{ }^{-3}, \mathrm{~K}=155 \mathrm{mg} \mathrm{dm}{ }^{-3}, \mathrm{MO}=45 \mathrm{~g} \mathrm{~kg}^{-1}, \mathrm{Al}=$ $9,7 \mathrm{mmol}_{\mathrm{c}} \mathrm{dm}^{-3}, \mathrm{Ca}=30 \mathrm{mmol}_{\mathrm{c}} \mathrm{dm}^{-3}, \mathrm{Mg}=$ $1,3 \mathrm{mmol}_{\mathrm{c}} \mathrm{dm}^{-3}, \mathrm{H}+\mathrm{Al}=69,7 \mathrm{mmol}_{\mathrm{c}} \mathrm{dm}^{-3}$, CTC efeti$\mathrm{va}=56 \mathrm{mmol}_{\mathrm{c}} \mathrm{dm}^{-3}$, CTC pH $7=116,4 \mathrm{mmol}_{\mathrm{c}} \mathrm{dm}^{-3}$, saturação por $\mathrm{Al}=17,0 \%$ e saturação por bases = 40,3 \%. Ainda em outubro de 2001 foram aplicadas, em superfície, $3 \mathrm{Mg} \mathrm{ha}^{-1}$ de calcário dolomítico ajustado para PRNT $100 \%$ e, em novembro de 2001, procedeu-se à dessecação da pastagem nativa e à implantação das culturas de soja e de milho, em sistema plantio direto.

O delineamento experimental utilizado foi o bifatorial $3 \times 2$, disposto em blocos ao acaso, com quatro repetições. A área de cada parcela foi de $60 \mathrm{~m}^{2}$, e a área total do experimento compreendeu 1,6 ha. $\mathrm{O}$ fator A foi constituído por três sistemas de manejo das pastagens de inverno: (1) Sem Pastejo (SP), (2) Pastejo a cada 28 dias (P28) e (3) Pastejo a cada 14 dias (P14). O fator A constou de duas culturas de verão: soja (Glycine Max (L.) Merr.) e milho (Zea mays L.). A pastagem foi formada por um consórcio de aveiapreta (Avena strigosa Schreb.) e azevém (Lolium multiflorum Lam.), na proporção de $80 \mathrm{~kg} \mathrm{ha}^{-1}$ de sementes viáveis de aveia-preta e $20 \mathrm{~kg} \mathrm{ha}^{-1}$ de sementes viáveis de azevém, semeadas durante o mês de abril de cada ano de condução do experimento, ou seja, 2002, 2003 e 2004. O azevém foi semeado a lanço e incorporado ao solo com a passagem de uma semeadora para plantio direto que continha as sementes de aveia-preta, semeadas em linha com 
espaçamento de $0,17 \mathrm{~m}$. Os pastejos foram realizados aos 60, 88 e 106 dias após emergência das pastagens para o sistema P28 e aos 60, 74, 88, 94 e 106 dias após emergência das pastagens para o sistema P14. Cada pastejo foi realizado utilizando-se bovinos com peso aproximado de $350 \mathrm{~kg}$ cada, com taxa de lotação variável média de 1.154 e $1.640 \mathrm{~kg} \mathrm{ha}^{-1}$ de peso dos animais vivos, para os tratamentos P28 e P14, respectivamente (Nicoloso et al., 2006). Os bovinos permaneciam na pastagem até esta atingir altura mínima, aproximada, de $0,10 \mathrm{~m}$, o que era alcançado com um período de aproximadamente $2 \mathrm{~h}$ de pastejo. Após o último pastejo, as pastagens eram diferidas pelo período de um mês, objetivando acúmulo de fitomassa para cobertura de solo, para em seguida se proceder à dessecação e realização da semeadura das culturas de verão. As pastagens de inverno não receberam adubação nitrogenada. As adubações fosfatada e potássica foram realizadas somente para as culturas de soja e de milho, conforme as indicações da CFS RS/SC (1995). O milho e a soja foram implantados no mês de novembro de cada ano. Para o milho, utilizou-se espaçamento entre linhas de $0,70 \mathrm{~m}$ e população de 55.000 plantas ha-1 e, para a soja, espaçamento de $0,35 \mathrm{~m}$ e população de 300.000 plantas $\mathrm{ha}^{-1}$. O milho recebeu $120 \mathrm{~kg} \mathrm{ha}^{-1}$ de $\mathrm{N}$, sendo $30 \mathrm{~kg} \mathrm{ha}^{-1}$ por ocasião da semeadura e o restante parcelado em duas aplicações. A soja foi inoculada com Rhizobium específico para a cultura. Os demais tratos culturais aplicados seguiram as recomendações técnicas vigentes no Estado do Rio Grande do Sul.

Para determinar a adição de matéria seca ao solo, em cada tratamento, durante os três anos de condução do experimento, e a matéria seca proveniente do campo nativo no início do período experimental, foram coletadas amostras da parte aérea vegetal, para posterior estimativa da produção de matéria seca. As amostras das pastagens de inverno foram coletadas no final do período reservado para o diferimento, com auxílio de um quadro de aço de $0,25 \mathrm{~m}^{2}$ de área interna. A cultura da soja foi amostrada quando as plantas se encontravam no estádio $\mathrm{R}_{4}$ (Padovan et al., 2002). A cultura do milho foi amostrada por ocasião da maturação fisiológica. Todas as avaliações foram constituídas por quatro repetições. O material coletado foi levado à estufa de ventilação forçada e seco a $60 \pm 5^{\circ} \mathrm{C}$, até que atingisse peso constante.

Durante o período de diferimento da pastagem do ano de 2004, mais precisamente no mês de outubro, foram realizadas coletas de duas amostras indeformadas de solo por parcela, nas profundidades de 0-0,05, 0,05-0,10 e 0,10-0,15 m, com auxílio de anéis de aço com volume conhecido, totalizando oito repetições por tratamento, em cada profundidade. Posteriormente, em laboratório, foram determinadas a densidade do solo (Ds), pelo método do anel volumétrico, a porosidade total $(\mathrm{Pt})$, pela percentagem de saturação por água do solo, e a microporosidade (Mi) e macroporosidade do solo (Ma), determinadas pela 'mesa de tensão' (Embrapa, 1997).
Por ocasião da coleta de solo, para determinação de suas propriedades físicas, também foi determinada a resistência mecânica do solo à penetração $(\mathrm{RP})$, em intervalos de $0,01 \mathrm{~m}$ até a profundidade de $0,20 \mathrm{~m}$, com 20 repetições por tratamento, utilizando para isso um penetrômetro digital, com ponta cônica de $30^{\circ}$. Concomitantemente, também foi determinada a umidade gravimétrica do solo, em três profundidades: 0-0,075, 0,075-0,15 e 0,15-0,20 m.

Ainda nesse período, foi realizada a avaliação da infiltração de água no solo, pelo método dos duplos anéis concêntricos, descrito em Embrapa (1997). Foram realizadas 11 repetições por tratamento, com duração de $2 \mathrm{~h}$ cada. A umidade gravimétrica do solo em cada sistema de pastejo, no momento da avaliação da infiltração, na camada de 0-0,10 m, foi de 0,275, 0,239 e $0,241 \mathrm{~m}^{3} \mathrm{~m}^{-3}$, para os tratamentos SP, P28 e $\mathrm{P} 14$, respectivamente. $\mathrm{O}$ anel externo tinha dimensões de $0,40 \mathrm{~m}$ de diâmetro e $0,15 \mathrm{~m}$ de altura, e o anel interno, de 0,20 $\mathrm{m}$ de diâmetro e 0,20 $\mathrm{m}$ de altura. Para medir o volume de água infiltrado no anel interno, utilizou-se um aparelho medidor confeccionado com um cano de PVC de 0,15 m de diâmetro e $1 \mathrm{~m}$ de comprimento, dotado de um piezômetro fixado sobre uma régua graduada em mililitros, semelhante ao descrito por Siqueira \& Denardin (1985). O nível de água do anel externo foi mantido manualmente, com uma lâmina de água de cerca de 0,05 $\mathrm{m}$ de altura. $\mathrm{O}$ equipamento foi denominado "Infiltrômetro Jari Grande" e está descrito em Lanzanova (2005) e Amado et al. (2005). O ajuste dos dados de infiltração de água no solo foi feito segundo a equação de Kostiakov (TI = $\mathrm{kt}^{\mathrm{a}}$ ), em que TI representa a taxa de infiltração de água no solo, em função do tempo $t$; os parâmetros $k$ e a são empíricos e não têm interpretação física (Clemmens, 1983).

Os resultados foram submetidos à análise de variância e comparação de médias pelo teste de Tukey a $5 \%$, e a análise de regressão foi usada para medir a taxa de infiltração de água no solo.

\section{RESULTADOS E DISCUSSÃO}

Os tratamentos, tanto de inverno (freqüência de pastejo) como de verão (soja e milho), proporcionaram diferentes adições de material vegetal à superfície do solo, ao longo dos três anos de condução do experimento (Quadro 1). À medida que a fertilidade do solo foi sendo melhorada, pela adubação mineral, pelos dejetos animais e pelo aporte constante de material vegetal, os índices de produtividade e, conseqüentemente, a produção de matéria seca das culturas de inverno e verão aumentaram. No entanto, observou-se efeito do pastejo na redução da produção de matéria seca das pastagens de inverno quando se aumentou a freqüência de pastejo, assim como ficou evidenciada maior adição de matéria seca pela cultura do milho 
Quadro 1. Adição anual de matéria seca, pelos resíduos vegetais, ao solo, como variável da freqüência de pastejo no inverno e das espécies cultivadas no verão

\begin{tabular}{|c|c|c|c|c|c|c|c|c|c|}
\hline \multirow{3}{*}{\multicolumn{2}{|c|}{ Tratamento }} & \multicolumn{7}{|c|}{ Ano } & \multirow{3}{*}{ Média } \\
\hline & & \multirow{2}{*}{$\frac{2001^{(1)}}{\text { Campo nativo }}$} & \multirow{2}{*}{$\frac{2002}{\text { Total }^{(2)}}$} & \multirow{2}{*}{$\frac{2003}{\text { Total }}$} & \multicolumn{4}{|c|}{2004} & \\
\hline & & & & & Pastagem & Soja & Milho & Total & \\
\hline \multirow[t]{2}{*}{$\mathrm{SP}$} & Soja & 4,63 & 10,98 & 13,33 & $10,37 \mathrm{a}^{(3)}$ & $4,52 \mathrm{a}$ & - & 14,88 & 10,94 \\
\hline & Milho & 4,63 & 12,17 & 17,90 & $10,90 \mathrm{a}$ & - & $12,75 \mathrm{a}$ & 23,65 & 14,60 \\
\hline \multirow[t]{2}{*}{$\mathrm{P} 28$} & Soja & 4,63 & 8,50 & 5,94 & $2,81 \mathrm{~b}$ & $4,06 \mathrm{ab}$ & - & 6,85 & 6,48 \\
\hline & Milho & 4,63 & 9,77 & 15,19 & $4,06 \mathrm{~b}$ & - & $11,50 \mathrm{ab}$ & 15,56 & 11,29 \\
\hline \multirow[t]{2}{*}{$\mathrm{P} 14$} & Soja & 4,63 & 6,38 & 5,40 & $2,31 \mathrm{~b}$ & $3,77 \mathrm{~b}$ & - & 6,08 & 5,62 \\
\hline & Milho & 4,63 & 8,29 & 11,13 & $2,98 \mathrm{~b}$ & - & $9,50 \mathrm{~b}$ & 12,48 & 9,13 \\
\hline
\end{tabular}

\footnotetext{
(1) Adição de matéria seca ao solo referente ao campo nativo por ocasião da implantação do experimento. ${ }^{(2)}$ Referente a soma da matéria seca da pastagem, soja e milho ${ }^{(3)}$ Médias seguidas por letras distintas, na mesma coluna, diferem pelo teste de Tukey $(\mathrm{p}<0,05)$. Obs.: SP: sem pastejo; P28: pastejo a cada 28 dias; P14: pastejo a cada 14 dias.
}

em comparação com a cultura da soja, no verão. Os diferentes níveis de adição de material vegetal sobre o solo resultaram em reflexos sobre alguns atributos físicos do solo, discutidos a seguir.

A compactação do solo decorrente do pisoteio bovino, durante os três anos de duração do estudo, segundo os valores de densidade do solo, limitou-se à camada superficial do solo, de 0-0,05 m de profundidade. Nas camadas subseqüentes, não houve diferença significativa entre os valores observados, e, para as três freqüências de pastejo, estes variaram entre 1,32 e 1,35 $\mathrm{Mg} \mathrm{m}^{-3}$ (Quadro 2). Trein et al. (1991), aplicando uma carga animal elevada (200 animais por hectare), durante reduzido período de tempo (40 h), num Argissolo Vermelho do RS sob pastagem de aveia-preta (Avena strigosa Schreber) + trevo (Trifolium subterraneum L.), também verificaram compactação do solo na camada superficial, com valores de densidade passando de 1,39 para $1,56 \mathrm{Mg} \mathrm{m}^{-3}$, antes e após a realização do pastejo, respectivamente.

A microporosidade do solo não foi, significativamente, alterada pelos sistemas de manejo das pastagens em nenhuma das camadas de solo estudadas. Contudo, a macroporosidade e a porosidade total sofreram influência do pisoteio bovino (Quadro 2). O pastoreio e a redução do intervalo, de 28 para 14 dias de pastejo, diminuíram significativamente a macroporosidade e a porosidade total na camada superficial, passando de 0,11 para 0,07 e de 0,56 para $0,51 \mathrm{dm}^{3} \mathrm{dm}^{-3}$, respectivamente, e ambas diferiram, significativamente, da área não-pastejada. No menor intervalo de pastejo usado (P14), a redução da macroporosidade foi da ordem de 2,5 vezes, quando comparados aos valores da área não-pastejada.
As áreas pastejadas com intervalo de 28 dias mantiveram valores de macroporosidade iguais ou superiores ao limite crítico de 0,10 $\mathrm{dm}^{3} \mathrm{dm}^{-3}$ (Letey, 1985; Silva et al., 1994) em todas as camadas, igualando-se ao sistema SP nas camadas inferiores. Em contrapartida, no sistema $\mathrm{P} 14$, verificaram-se valores baixos de macroporosidade $\left(0,07 \mathrm{dm}^{3} \mathrm{dm}^{-3}\right)$ em todas as camadas, inferiores, portanto, ao limite crítico, o que aumenta o risco de déficit de $\mathrm{O}_{2}$ às raízes e reduz a continuidade de poros e a permeabilidade do solo. A observância de efeitos da freqüência de pastejo na macroporosidade e porosidade total, em maiores profundidades, em comparação com a densidade do solo e a microporosidade, deve-se ao fato de estas serem propriedades mais sensíveis e susceptíveis ao processo de compactação do solo (Hillel, 1982).

Com exceção da camada de $0-0,05 \mathrm{~m}$ de profundidade, tanto para a porosidade quanto para a densidade do solo, não foi verificada influência significativa da cultura antecedente às pastagens. Nessa camada, entretanto, a ação do sistema radicular da soja proporcionou valores de macroporosidade ligeiramente superiores aos encontrados nas pastagens em rotação com o milho. Por outro lado, quando a cultura antecessora foi o milho, os valores de microporosidade foram incrementados. As alterações observadas, embora ainda de baixa magnitude, são provavelmente provenientes da ação diferenciada do sistema radicular das plantas pertencentes às famílias botânicas das leguminosas e gramíneas. Segundo Venzke Filho et al. (2004), não apenas o crescimento e a ação das raízes dessas plantas são diferenciados, mas também a massa de raízes por volume de solo, ou seja, a densidade radicular, bem como a distribuição espacial. Avalian- 
Quadro 2. Densidade do solo (Ds), macroporosidade (Ma), microporosidade (Mi) e porosidade total (Pt) de um Argissolo Vermelho-Amarelo alumínico sob diferentes sistemas de manejo de uma pastagem de inverno e das culturas de soja e milho no verão, em outubo de 2004, após três anos de condução

\begin{tabular}{|c|c|c|c|c|}
\hline Sistema de manejo / cultura antecessora & Ds & Ma & Mi & $\mathbf{P t}$ \\
\hline & $\mathrm{Mg} \mathrm{m}^{-3}$ & \multicolumn{3}{|c|}{$\mathrm{dm}^{3} \mathrm{dm}^{-3}$} \\
\hline & \multicolumn{4}{|c|}{ Profundidade $0,0-0,05 \mathrm{~m}$} \\
\hline Sem pastejo & $1,00 \mathrm{~b}^{(1)}$ & 0,18 a & 0,42 & $0,60 \mathrm{a}$ \\
\hline Pastejos a cada 28 dias & 1,16 a & $0,11 \mathrm{~b}$ & 0,45 & $0,56 \mathrm{~b}$ \\
\hline Pastejos a cada 14 dias & $1,20 \mathrm{a}$ & $0,07 \mathrm{c}$ & 0,44 & $0,51 \mathrm{c}$ \\
\hline F (sistema de manejo) & $11,70^{*}$ & $30,88^{*}$ & $2,33^{\mathrm{ns}}$ & $16,67^{*}$ \\
\hline Soja & 1,10 & 0,13 a & $0,42 \mathrm{~b}$ & 0,56 \\
\hline Milho & 1,14 & $0,11 \mathrm{~b}$ & $0,44 \mathrm{a}$ & 0,55 \\
\hline F (cultura antecessora) & $4,32^{\mathrm{ns}}$ & $7,21^{*}$ & $4,88^{*}$ & $2,36^{\mathrm{ns}}$ \\
\hline F (interação sistema x cultura) & $1,76^{\mathrm{ns}}$ & $0,82^{\mathrm{ns}}$ & $2,50^{\mathrm{ns}}$ & $0,40^{\mathrm{ns}}$ \\
\hline Campo nativo & 1,09 & 0,21 & 0,40 & 0,62 \\
\hline \multirow[t]{2}{*}{ CV (\%) } & 5,80 & 29,46 & 6,38 & 4,28 \\
\hline & \multicolumn{4}{|c|}{ Profundidade $0,05-0,10 \mathrm{~m}$} \\
\hline Sem pastejo & 1,33 & $0,10 \mathrm{a}$ & 0,39 & $0,49 \mathrm{a}$ \\
\hline Pastejos a cada 28 dias & 1,35 & $0,10 \mathrm{a}$ & 0,39 & 0,49 a \\
\hline Pastejos a cada 14 dias & 1,32 & $0,07 \mathrm{~b}$ & 0,39 & $0,46 \mathrm{~b}$ \\
\hline F (sistema de manejo) & $1,32^{\mathrm{ns}}$ & $6,00^{*}$ & $0,13^{\mathrm{ns}}$ & $8,88^{*}$ \\
\hline Soja & 1,34 & 0,09 & 0,39 & 0,48 \\
\hline Milho & 1,33 & 0,08 & 0,40 & 0,48 \\
\hline F (cultura antecessora) & $0,65^{\mathrm{ns}}$ & $8,59^{*}$ & $4,68^{*}$ & $1,49^{\mathrm{ns}}$ \\
\hline F (interação sistema x cultura) & $2,11^{\mathrm{ns}}$ & $0,09^{\text {ns }}$ & $0,01^{\mathrm{ns}}$ & $0,05^{\mathrm{ns}}$ \\
\hline Campo nativo & 1,33 & 0,18 & 0,39 & 0,57 \\
\hline \multirow[t]{2}{*}{ CV (\%) } & 2,58 & 17,63 & 3,26 & 3,07 \\
\hline & \multicolumn{4}{|c|}{ Profundidade $0,10-0,15 \mathrm{~m}$} \\
\hline Sem pastejo & 1,33 & $0,10 \mathrm{a}$ & 0,39 & 0,49 a \\
\hline Pastejos a cada 28 dias & 1,33 & $0,10 \mathrm{a}$ & 0,38 & 0,49 a \\
\hline Pastejos a cada 14 dias & 1,32 & $0,07 \mathrm{~b}$ & 0,39 & $0,45 \mathrm{~b}$ \\
\hline F (sistema de manejo) & $0,09^{\mathrm{ns}}$ & $4,58^{*}$ & $0,13^{\mathrm{ns}}$ & $10,58^{*}$ \\
\hline Soja & 1,33 & 0,09 & 0,38 & 0,48 \\
\hline Milho & 1,33 & 0,08 & 0,39 & 0,48 \\
\hline F (cultura antecessora) & $0,01^{\mathrm{ns}}$ & $1,95^{\mathrm{ns}}$ & $1,66^{\mathrm{ns}}$ & $0,57^{\mathrm{ns}}$ \\
\hline F (interação sistema x cultura) & $2,42^{\mathrm{ns}}$ & $1,36^{\mathrm{ns}}$ & $4,27^{*}$ & $0,11^{\mathrm{ns}}$ \\
\hline Campo nativo & 1,24 & 0,20 & 0,36 & 0,57 \\
\hline $\mathrm{CV}(\%)$ & 4,03 & 23,62 & 3,82 & 3,10 \\
\hline
\end{tabular}

(1) Médias seguidas por letras distintas, na mesma coluna e profundidade, diferem pelo teste Tukey $(p<0,05) .{ }^{*}$ Teste $\mathrm{F}$ significativo $(p<0,05) .{ }^{\text {ns }}$ Teste $F$ não-significativo.

do o sistema radicular da soja e do milho, em solo de textura argilosa, os autores citados encontraram, na camada de $0-0,10 \mathrm{~m}$, distribuição de 36 e $30 \%$ do sistema radicular total, para milho e soja, respectivamente. No entanto, diferenças significativas foram encontradas quanto às características das raízes nessa camada. Enquanto o milho apresentou $28 \%$ de raízes finas (diâmetro menor que 1,2 $\mathrm{mm}$ ), a soja apresentou $92 \%$, o que ocasiona maior contato solo-raiz e maior exploração do perfil por elas. 
Os sistemas de manejo da pastagem de inverno influenciaram os valores de resistência mecânica do solo à penetração, em toda a camada avaliada. Constatou-se que os valores de RP no sistema SP não ultrapassaram 1,66 MPa, observado na profundidade de $0,13 \mathrm{~m}$, diferindo, significativamente, dos sistemas P28 e P14, que atingiram valores máximos de 2,49 e $2,61 \mathrm{MPa}$ nas profundidades de 0,05 e $0,08 \mathrm{~m}$, respectivamente (Figura 1). Esses resultados confirmam os dados de Trein et al. (1991), que limitam a $0-0,075 \mathrm{~m}$ a camada afetada pelo pisoteio bovino. Também Clark et al. (2004), realizando experimento envolvendo pastoreio em resteva de lavoura de milho, em intervalos de 28 dias, encontraram valores de $R P$ de 21 a $44 \%$ superiores, em relação às áreas nãopastejadas. Os valores encontrados nos sistemas P14 e P28 situam-se acima do limite crítico de $2 \mathrm{MPa}$ proposto por Taylor et al. (1966). Lipiec \& Hatano (2003) confirmam que valores de resistência à penetração variando de 1 a $1,7 \mathrm{MPa}$ começam a provocar redução do crescimento radicular, e que valores entre 3 e $4 \mathrm{MPa}$ causam paralisação do crescimento das raízes. Isso depende do tipo de solo e de distribuição do tamanho de poros, especialmente quando, para medição, se utiliza cone de diâmetro maior que o diâmetro das raízes.

Parte da diferença de RP observada entre os tratamentos pode ser atribuída à variável umidade do solo (Figura 2). Essas diferenças na umidade do solo devem-se, sobretudo, à quantidade de matéria seca remanescente como cobertura de solo em cada área. Não foram percebidas diferenças significativas nos valores de RP entre as áreas precedidas de soja ou de milho no verão anterior (Figura 1).

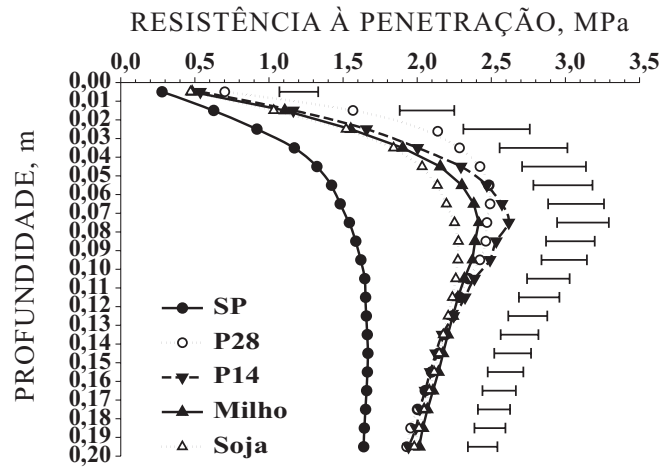

Figura 1. Resistência à penetração mecânica, avaliada por penetrômetro digital, de um Argissolo Vermelho-Amarelo alumínico em diferentes sistemas de manejo de uma pastagem de inverno (SP: sem pastejo; P28: pastejo a cada 28 dias; P14: pastejo a cada 14 dias). As barras horizontais correspondem à diferença mínima significativa apenas entre os sistemas de manejo das pastagens de inverno pelo teste de Tukey $(p<0,05)$. Diferenças entre espécies cultivadas de verão (milho e soja) não foram significativas pelo teste $F(p<0,05)$.
A avaliação de infiltração de água no solo foi o atributo físico mais sensível em diferenciar os tratamentos investigados, tanto no que diz respeito à freqüência de pastejo quanto à cultura de verão precedente (Figura 3). O coeficiente de variação médio encontrado na avaliação da taxa de infiltração de água no solo foi de 73,45 \%. Esse valor é aparentemente alto, mas considerado normal para o método usado (Warrick \& Nielsen, 1980). Desse modo, foi evidenciado o efeito negativo do pisoteio bovino quando se elevou a freqüência de pastejo, reduzindo significativamente a taxa inicial de infiltração de água no solo e, conseqüentemente, a lâmina infiltrada acumulada.

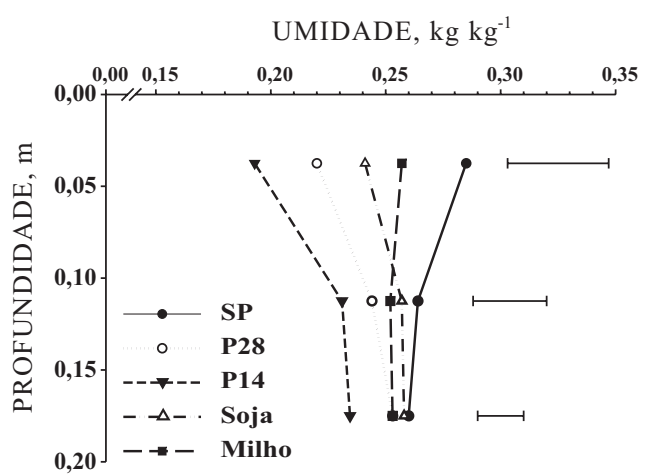

Figura 2. Umidade gravimétrica de um Argissolo Vermelho-Amarelo alumínico sob diferentes sistemas de manejo de uma pastagem de inverno (SP: sem pastejo; P28: pastejo a cada 28 dias; P14: pastejo a cada 14 dias). As barras horizontais correspondem à diferença mínima significativa entre os sistemas de manejo da pastagem de inverno pelo teste de Tukey $(p<0,05)$.

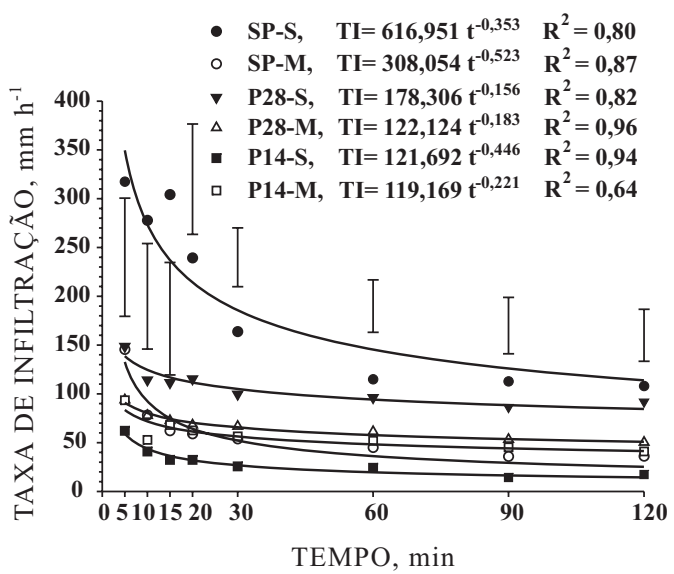

Figura 3. Taxa de infiltração de água em um Argissolo Vermelho-Amarelo alumínico sob diferentes sistemas de manejo de uma pastagem de inverno, tendo como culturas de verão antecessoras soja e milho (SP: sem pastejo; P28: pastejo a cada 28 dias; P14: pastejo a cada 14 dias; S: soja; M: milho). As barras verticais correspondem à diferença mínima significativa pelo teste de Tukey $(\mathrm{p}<0,05)$. 
A importância da cultura antecessora às pastagens de inverno, na taxa de infiltração de água no solo, foi mais evidente nas áreas onde se cultivou milho, em comparação à soja. No tratamento P14, o aporte médio de matéria seca de milho foi de $9,50 \mathrm{Mg} \mathrm{ha}^{-1}$, e o de soja, de $3,77 \mathrm{Mg} \mathrm{ha}^{-1}$. Assim, com a soja proporcionando apenas $39,7 \%$ da quantidade de matéria seca aportada pelo milho, o efeito da maior freqüência de animais sobre a parcela resultou em redução da infiltração de água no solo. Outro resultado a ser destacado é que, com o aporte de matéria seca de milho de $12,75,11,50$ e $9,50 \mathrm{Mg}^{-1}{ }^{-1}$ nos sistemas $\mathrm{SP}$, P28 e P14, respectivamente, não houve diferença significativa na infiltração de água entre os sistemas de manejo da pastagem de inverno (Figura 3). Esse resultado sugere que a quantidade de resíduos de milho foi suficiente para prevenir prejuízos à infiltração de água induzidos pela freqüência de pastejo. Por outro lado, nos tratamentos que receberam a cultura da soja - com aporte médio de matéria seca de 4,52, 4,06 e 3,77 Mg ha-1, para os sistemas SP, P28 e P14, respectivamente - observou-se redução significativa na taxa de infiltração de água no solo quando se aplicou maior freqüência de pastejo (P14), refletindo a menor proteção do solo pelos resíduos culturais desta cultura. Ainda assim, com menor freqüência de pastejo (P28) ou no tratamento sem pastejo (SP), obteve-se a maior taxa de infiltração (Figura 3). Atribui-se o fato ao sistema radicular da soja, que favoreceu a infiltração de água, sendo esse resultado coerente com a maior macroporosidade do solo em relação ao milho (Quadro 2). Contudo, devido à menor quantidade de resíduos aportados pela soja, constatou-se maior susceptibilidade à redução da infiltração de água no solo quando se utilizou maior freqüência de pastejo (P14) (Figura 3).

A redução na infiltração de água no solo pode ser relacionada com o incremento da densidade e redução da macroporosidade do solo na camada superficial, sobretudo nas áreas pastejadas com maior freqüência (P14) (Quadro 2). Cassol (2003) e Trein et al. (1991) também observaram efeito do pisoteio bovino na densidade e na macroporosidade do solo, com conseqüente diminuição da taxa de infiltração de água. Ainda, segundo o último autor, o tipo de manejo aplicado no presente trabalho, com alta lotação animal e limitada permanência dos bovinos nas áreas de pastagem, exerce efeito praticamente instantâneo nos atributos físicos do solo, principalmente na macroporosidade, que é a principal reguladora do fluxo de água no solo. O prejuízo ocasionado pelos cascos dos animais, durante o pastejo, na estrutura da camada superficial do solo também foi relatado anteriormente por Bertol et al. (1998), após testarem diferentes níveis de oferta de forragem e, conseqüentemente, de intensidade de pisoteio bovino na mesma área.

Os atributos físicos do solo investigados, de maneira geral, foram eficientes em detectar o processo de compactação induzido pelo pisoteio bovino, sendo que a resistência do solo à penetração, a macroporosidade e a infiltração de água no solo foram atributos mais sensíveis que a densidade do solo na diferenciação dos tratamentos avaliados.

Os resultados encontrados neste trabalho reforçam o entendimento de que, em sistema de integração lavoura-pecuária sob sistema plantio direto, deve-se ter cuidado especial no manejo do pastejo para que os atributos físicos do solo não sejam alterados para condição inferior de qualidade.

\section{CONCLUSÕES}

1. Os sistemas de pastejo testados proporcionaram compactação de solo na camada de $0-0,05 \mathrm{~m}$, quando avaliada pela densidade do solo, e nas camadas de $0-0,15$ e $0-0,20 \mathrm{~m}$, quando avaliadas pela macroporosidade do solo e porosidade total do solo, respectivamente. A avaliação de resistência do solo à penetração evidenciou compactação de solo na camada de $0-0,20 \mathrm{~m}$.

2. A redução do intervalo entre pastejos, de 28 para 14 dias, após a cultura da soja, reduziu a taxa de infiltração de água no solo.

3. Os sistemas de pastejo avaliados (sem pastejo, pastejo a cada 28 dias e pastejo a cada 14 dias) não influenciaram a taxa de infiltração de água no solo após a cultura de milho, devido ao elevado aporte e manutenção de resíduos culturais na superfície do solo.

\section{AGRADECIMENTOS}

Ao Sr. José Nicoloso e família, proprietário da Agropecuária Capitão Rodrigo, por ceder a área destinada ao experimento e pelo apoio na execução deste; à CAPES e ao CNPq, pela concessão das bolsas dos envolvidos neste trabalho; aos bolsistas de iniciação científica e voluntários: Vitor Girardello, Jardes Bragagnolo, Vagner Lopes da Silva, Gustavo Bellé, Felipe Facco e Ricardo Schenato, pelo auxílio na realização deste trabalho.

\section{LITERATURA CITADA}

ABREU, S.L.; REICHERT, J.M. \& REINERT, D.J. Escarificação mecânica e biológica para a redução da compactação em argissolo franco-arenoso sob plantio direto. R. Bras. Ci. Solo, 28:519-531, 2004.

ALBUQUERQUE, J.A.; SANGOI, L. \& ENDER, M. Efeitos da integração lavoura-pecuária nas propriedades físicas do solo e características da cultura do milho. R. Bras. Ci. Solo, 25:717-723, 2001. 
AMADO, T.J.C., NICOLOSO, R.S., LANZANOVA, M.E., SANTI, A.L. \& LOVATO, T. A compactação pode comprometer os rendimentos de áreas sob plantio direto. Revista Plantio Direto, edição 89, Setembro/Outubro de 2005. Aldeia Norte, Passo Fundo - RS.

BASSANI, H.J. Propriedades físicas induzidas pelo plantio direto e convencional em área pastejada e não-pastejada. Santa Maria, Universidade Federal de Santa Maria, 1996. 90p. (Tese de Mestrado)

BERTOL, I.; GOMES, K.E.; DENARDIN, R.B.N.; MACHADO, L.A.Z. \& MARASCHIN, G.E. Propriedades físicas do solo relacionadas a diferentes níveis de oferta de forragem numa pastagem natural. Pesq. Agropec. Bras., 33:779. 786,1998

BETTERIDGE, K.; MACKAY, A.D.; SHEPHERD, T.G.; BARKER, D.J.; BUDDING, P.J.; DEVANTIER, B.P. \& COSTALL, D.A. Effect of cattle and sheep treading on surface configuration of a sedimentary hill soil. Aust. J. Soil Res., 37:743-760, 1999.

BRAIDA, J.A.; REICHERT, J.M.; SOARES, J.A.D.; REINERT, D.J.; SEQUINATO, L. \& KAISER, D.R. Relações entre a quantidade de palha existente sobre o solo e a densidade máxima obtida no ensaio Proctor. In: REUNIÃO BRASILEIRA DE MANEJO E CONSERVAÇÃO DO SOLO E DA ÁGUA, 15., Santa Maria, 2004. Anais. Santa Maria, Sociedade Brasileira de Ciência do Solo, 2004. CDROM

BRASIL. Ministério da Agricultura. Divisão de Pesquisa Pedológica. Levantamento e reconhecimento dos solos do Estado do Rio Grande do Sul. Recife, MA-DPP/AS DRNR/INCRA-RS, 1973. 431p.

CASSOL, L.C. Relações solo-planta-animal num sistema de integração lavoura-pecuária em semeadura direta com calcário na superfície. Porto Alegre, Universidade Federal do Rio Grande do Sul, 2003, 143p. (Tese de Doutorado)

CLARK, J.T.; RUSSELL, J.R.; KARLEN, D.L.; SINGLETON, P.L.; BUSBY, W.D. \& PETERSON, B. C. Soil surface property and soybean yield response to corn stover grazing. Agron. J., 96:1364-1371, 2004.

CLEMMENS, A.J. Infiltration equation for border irrigation models. In: NATIONAL CONFERENCE ON ADVANCES IN INFILTRATION, 1983, Chicago. Proceedings. St. Joseph, American Society of Agricultural Engineers, 1983. p.266-274. (ASAE Publication, 11-83. Advances in Infiltration)

COMISSÃO DE FERTILIDADE DO SOLO - CFSRS/SC Recomendações de adubação e calagem para os estados do Rio Grande do Sul e Santa Catarina. 3.ed. Passo Fundo, Sociedade Brasileira de Ciência do Solo - Núcleo Regional Sul; Embrapa/CNPT, 1995. 224p.

CORREA, J.C. \& REICHARDT, K. Efeito do tempo de uso das pastagens sobre as propriedades de um Latossolo Amarelo da Amazônia Central. Pesq. Agropec. Bras., 30:107-114, 1995.

EMPRESA BRASILEIRA DE PESQUISA AGROPECUÁRIA EMBRAPA. Centro Nacional de Pesquisa de Solos. Manual de métodos de análise de solo. 2.ed. Brasília, 1997. 212p. (Embrapa/CNPS. Documentos, 1)
EMPRESA BRASILEIRA DE PESQUISA AGROPECUÁRIA EMBRAPA. Centro Nacional de Pesquisa de Solos. Sistema Brasileiro de Classificação de Solos. Brasília, 1999, $412 \mathrm{p}$.

FLORES, J.P.C. Atributos de solo e rendimento de soja em um sistema de integração lavoura-pecuária com diferentes pressões de pastejo em plantio direto com aplicação de calcário em superfície. Porto Alegre, Universidade Federal do Rio Grande do Sul, 2004. 74p. (Tese de Mestrado)

HILLEL, D. Introduction to soil physics. San Diego, Academic, 1982. 264p.

INSTITUTO BRASILEIRO DE GEOGRAFIA E ESTATÍSTICA - IBGE. Censo Agropecuário 1996. Disponível em: <http:/ /www.ibge.br>. Acesso em 01.10.2004. 1996.

LANZANOVA, M.E. Atributos físicos do solo em sistemas de culturas sob plantio direto na integração lavoura-pecuária. Santa Maria, Universidade Federal de Santa Maria, 2005. 132p. (Tese de Mestrado)

LEÃO, T.P.; SILVA, A.P.; MACEDO, M.C.M.; IMHOFF, S. \& EUCLIDES, V.P.B. Intervalo hídrico ótimo na avaliação de sistemas de pastejo contínuo e rotacionado. R. Bras. Ci. Solo, 28:415-423, 2004.

LENZI, A. Desempenho animal e produção de forragem em dois sistemas de uso da pastagem: Pastejo contínuo \& pastoreio racional Voisin. Florianópolis, Universidade Federal de Santa Catarina, 2003. 122 p. (Tese de Mestrado)

LEONARDO, H.C.L. Indicadores da qualidade do solo e água para a avaliação do uso sustentável da microbacia hidrográfica do rio Passo Cue, região oeste do Estado do Paraná. Piracicaba, Escola Superior de Agricultura Luiz de Queiroz, 2003. 121p. (Tese de Mestrado)

LETEY, J. Relationship between soil physical properties and crop production. Adv. Soil Sci., 1:277-294, 1985.

LIPIEC, J. \& HATANO, R. Quantification of compaction effects on soil physical properties and crop growth. Geoderma, 116:107-136, 2003.

MARSCHNER, H. Mineral nutrition of higher plants. 2.ed. London, Academic Press, 1995. p.508-536.

MOOJEN, E.L. \& MARASCHIN, G.E. Potencial produtivo de uma pastagem nativa do Rio Grande do Sul submetida a níveis de oferta de forragem. Ci. Rural, 32:127-132, 2002.

MORAES, A. \& LUSTOSA, S.B.C. Efeito do animal sobre as características do solo e a produção da pastagem. In: SIMPÓSIO SOBRE AVALIAÇÃO DE PASTAGENS COM ANIMAIS, 1997, Maringá. Anais. Maringá, Universidade Estadual de Maringá, 1997. p.129-149.

MORAES, W.V. Comportamento de características e propriedades de um Latossolo Vermelho-Escuro, submetido a diferentes sistemas de cultivo. Lavras, Escola Superior de Agricultura de Lavras, 1984. 107p. (Tese de Mestrado) 
MÜLLER, M.M.L.; CECCON, G. \& ROSOLEM, C.A. Influência da compactação do solo em subsuperfície sobre o crescimento aéreo e radicular de plantas de adubação verde de inverno. R. Bras. Ci. Solo, 25:531-538, 2001.

NICOLOSO, R.S. Dinâmica da matéria orgânica do solo em áreas de integração lavoura-pecuária sob sistema plantio direto. Santa Maria, Universidade Federal de Santa Maria, 2005. 149p. (Tese de Mestrado)

NICOLOSO, R.S.; LANZANOVA, M.E. \& LOVATO, T. Manejo das pastagens de inverno e potencial produtivo de sistemas de integração lavoura-pecuária no Estado do Rio Grande do Sul. Ci. Rural, 36:1799-1805, 2006.

PADOVAN, M.R.; ALMEIDA, D.L.; GUERRA, J.G.M.; RIBEIRO, R.L.D. \& NDIAYE, A. Avaliação de cultivares de soja, sob manejo orgânico, para fins de adubação verde e produção de grãos. Pesq. Agropec. Bras., 37:1705-1710, 2002.

ROSOLEM, C.A.; VALE, L.S.R.; GRASSI FILHO, H. \& MORAES, M.H. Sistema radicular e nutrição do milho em função da calagem e da compactação do solo. R. Bras. Ci. Solo, 18:491-497, 1994.

SAS INSTITUTE. Statistical Analysis System Institute - SAS/ STAT Procedure guide for personal computers. Version 5, Cary, NC. 1991.
SILVA, A.P.; KAY, B.D. \& PERFECT, E. Characterization of the least limiting water range. Soil Sci. Soc.Am. J., 58:1775-1781, 1994.

SIQUEIRA, O.J.F. \& DENARDIN J.E. Equipamento para medir a taxa de infiltração de água no solo utilizando anéis concêntricos em um sistema com nível de água constante. R. Bras. Ci. Solo, 9:73-75, 1985.

TAYLOR, H.M.; ROBERTSON, G.M. \& PARKER, J.J. Soil strength root penetration relations for medium to coarse textured soil materials. Soil Sci., 102:18-22, 1966.

TREIN, C.R.; COGO, N.P. \& LEVIEN, R. Métodos de preparo do solo na cultura do milho e ressemeadura do trevo na rotação aveia + trevo/milho, após pastejo intensivo. R. Bras. Ci. Solo, 15:105-111, 1991.

VENZKE FILHO, S.; FEIGL, B.; PICCOLO, M.; FANTE Jr, L.; NETO, M. \& CERRI, C. Root systems and microbial biomass under no-tillage system. Sci. Agric., 61:529-537, 2004 .

WARRICK A.W. \& NIELSEN, D.R. Spatial variability of soil physical properties in the field. In: HILLEL, D., ed. Application of soil physics. New York, Academic Press, 1980. 